\title{
ФАКТОРНАЯ МОДЕЛЬ УСТОЙЧИВОСТИ ЧЕЛОВЕКА И ОБЪЕКТИВНЫЕ МЕТОДИКИ ОЦЕНКИ
}

\section{FACTORIAL MODEL OF STABILITY OF THE PERSON AND OBJECTIVE TECHNIQUES OF THE ASSESSMENT \\ V. Kazankov}

Summary: Originally in article determination of stability of the person from the point of view of "Stability psychology» is formulated. This definition is key in psychological research of such phenomenon as stability. Definition presented the main components of stability: psychophysiological, psychological and psychosocial. Each component is briefly opened in this article. The presented components are by the author the basis for factorial model of stability of the person described and illustrated in article. Such concepts as biopsychosocial system of the person, biotechnosociety, activity are also considered. Proceeding from factorial model of stability, in the second part of article, the author's image on the express is shown to techniques of objective and subjective diagnosing of stability of the person at psychophysiological, psychological and psychosocial level. These techniques do not demand the special equipment, electronic programs for inspection. Conclusions are presented in the conclusion under article.

Keywords: sustainability, the psychology of sustainability, man, human biopsychosocial system, biotechnosociety, marker, process.
Казанков Вячеслав Владимирович

К.n.н., докторант, Санкт-Петербургский Университет Государственной противопожарной службы МЧС России; генеральный директор, ООО «Первый Легион», Санкт-Петербург legionfirst@mail.ru

Аннотация: Первоначально в статье сформулировано определение устойчивости человека с точки зрения «Психологии устойчивости». Данное определение является ключевым в психологическом исследовании такого феномена как устойчивость. Определением представлены основные компоненты устойчивости: психофизиологический, психологический и психосоциальный. Каждый компонент кратко раскрыт в данной статье. Представленные компоненты положены автором в основу факторной модели устойчивости человека описанной и проиллюстрированной в статье. Также рассмотрены такие понятия как биопсихосоциальная система человека, биотехносоциум, жизнедеятельность. Исходя из факторной модели устойчивости, во второй части статьи, показано авторское виденье по экспресс методикам объективного и субъективного диагностирования устойчивости человека на психофизиологическом, психологическом и психосоциальном уровне. Данные методики не требуют специального оборудования, электронных программ для обследования. В заключении представлены выводы по статье.

Ключевые слова: устойчивость, психология устойчивости, человек, биопсихосоциальная система человека, биотехносоциум, маркер, процесс.

спасателей 200 (16,7\%); полицейских 150 (12,5\%).

Устойчивость человека - это его способность к сохранению здоровья на психофизиологическом, психологическом и психосоциальном уровнях жизнедеятельности под воздействием разрушителей [4, с.303].

Здоровье есть состояние физического, душевного и социального благополучия [5]. То есть, в широком смысле если человек здоров, - значит, он устойчив; если человек нездоров, - значит, он неустойчив. В «Психологии устойчивости» [6, с.270-281] выделяют уровни психофизиологического, психологического и психосоциального здоровья, образующие биопсихосоциальную систему устойчивости человека. Жизнедеятельность представляет собой совокупность активности человека как индивида, личности и субъекта труда, объединенных понятиями «жизнь» и «деятельность». Под разрушителями следует понимать всё то, что направлено на повреждение и (или) уничтожение здоровья человека.

Из определения устойчивости человека следуют три основных фактора влияющих на здоровье: психофизио- 
логический, психологический и психосоциальный. Эти факторы образуют единство индивида, личности и субъекта труда в построении общей стратегии устойчивости человека в биотехносоциуме. Под биотехносоциумом следует понимать мир всей природы, техники, общества.

Психофизиологический уровень (фактор 1) является фактором функционирования физиологических особенностей нервной системы: сила или слабость, подвижность или инертность, уравновешенность или неуравновешенность. Они характеризуют темперамент индивида процессами возбуждения и торможения нервной системы. Этому фактору свойственны познавательные психические процессы в виде ощущения, восприятия, памяти и внимания.

Фактор психологического уровня (фактор 2) зависит от проявления познавательных психических процессов в виде представления, воображения, мышления и речи. Они, через призму эмоциональных психических процессов (эмоции, аффекты, чувства, настроение и эмоциональный стресс), формируют определенные психические состояния личности.

Психосоциальный уровень (фактор 3) - это фактор волевого психического процесса субъекта труда. Он проявляется в волевом действии по достижению целей, путем проявления характера в реализации мотивов и установок в биотехносоциуме.

Рассмотренные уровни образуют несколько иную факторную модель устойчивости человека (рис.1) чем она представлена в работе [7].

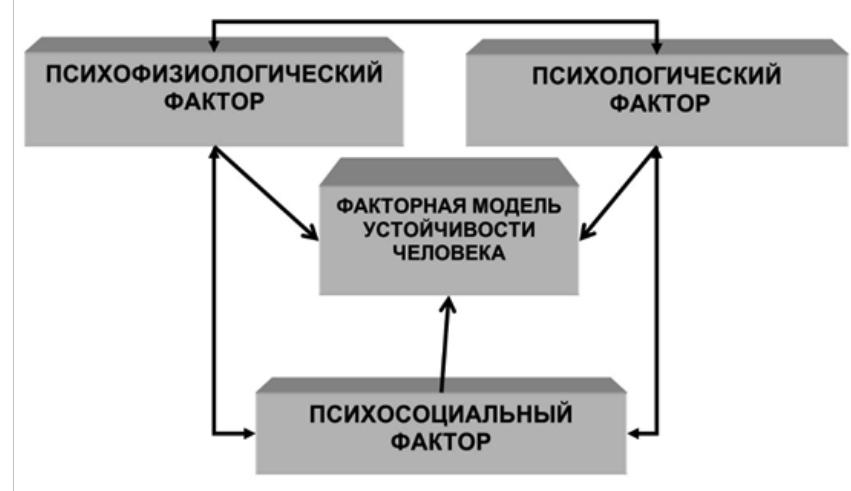

Рис. 1. Факторная модель устойчивости человека.

Отметим, что в ходе исследования, на начальном этапе, респондентам был задан вопрос: «Можете ли вы указать, что влияет на вашу устойчивость?». 64\% респондентов указало на физическое здоровье, $27 \%$ выделило психологическое состояние и 9\% на положение в обществе и наличие материальных благ. Эти сведенья навели на мысль о возможности применения пропорции золотого сечения. Важным в пропорции является соотноше- ние трех частей: целое так относится к своей большей части, как эта большая часть относится к меньшей части целого. То есть, психофизиологический уровень (целое - 100\%) так относится к психологическому уровню (большая часть - 61,8\%), как психологический уровень относится к психосоциальному уровню (меньшая часть целого - 38,2\%) (рис. 2).

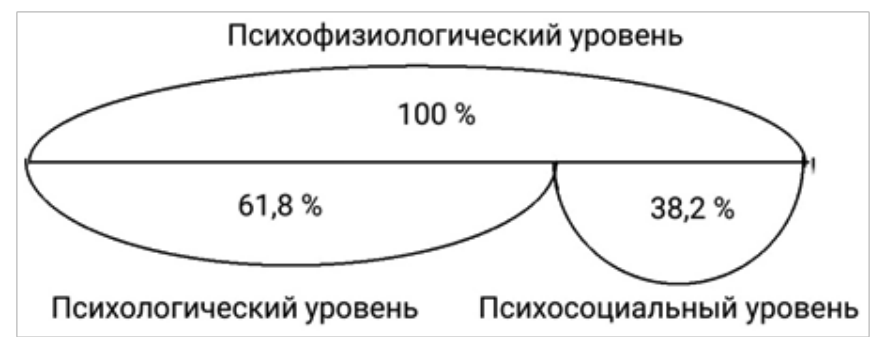

Рис. 2. Факторная модель устойчивости человека по принципу золотого сечения.

Иллюстрация на рис.2 наглядно показывает приоритетность факторов в факторной модели, их влияние на устойчивость человека. В виде золотой пропорции это записывается следующим образом:

$\frac{100 \text { (психофизиологический ур.) }}{61,8 \text { (психологический ур.) }}=\frac{61,8 \text { (психологический ур.) }}{38,2 \text { (психосоциальный ур.) }}=1,618$ (1)

Пропорция (1) визуализирует взаимосвязь трех факторов в биопсихосоциальной системе человека. Дроби пропорции указывают на пары для исследования, формирования и развития устойчивости человека. К примеру, развивая психофизиологическую устойчивость, мы развиваем психологическую устойчивость. И наоборот, развивая психологическую устойчивость, мы развиваем психофизиологическую устойчивость. Тоже происходит и со второй дробью. Развивая психологическую устойчивость, мы развиваем психосоциальную устойчивость. И, развивая психосоциальную устойчивость, мы развиваем психологическую устойчивость. Однако, нельзя развить психосоциальную устойчивость через психофизиологическую минуя психологическую. Нельзя и психофизиологическую устойчивость развивать через психосоциальную игнорируя психологическую. Но, развивая психологическую устойчивость мы сразу можем развивать и психофизиологическую и психосоциальную устойчивость. Следовательно, психологическая устойчивость (фактор 2) является связующим между психофизиологическим и психосоциальным факторами. Мы предполагаем, что фактор 2 связан с фактором 1 и фактором 3 психическими процессами (рис. 3).

Из рис. 3 видно, что психические процессы являются тем связующим звеном между тремя факторами. Подход к оценке устойчивости человека должен основываться на анализе психофизиологических, психологических и психосоциальных факторов. Данные факторы анализируются в тестовых подходах исследования устойчивости 
человека $[8,9,10]$. При этом диагностика в психологии, в большей степени, опирается на собственное описание симптомов обследуемых, что доказано экспериментом Д.Л. Розенхана [11, с.136-137].

Входе исследования нами были установлены следующие объективные методики оценки устойчивости человека на психофизиологическом, психологическом и психосоциальном уровнях.

Психофизиологический уровень - регистрация маркеров физиологических и психических реакций индивида, когда возможно установить неустойчивость человека по маркерам со знаком минус.

\section{Физиологические маркеры.}

Маркеры сердечно-сосудистой системы индивида: 1) отклонение артериального давления от нормы, что четко чувствуется индивидом; 2) отклонение частоты сердечных сокращений от нормы, что чувствуется индивидом; 3) четкое ощущение сердцебиения.

Маркеры реакции глаз: 1) частое мигание (моргание); 2) активность глазных движений, отражающие взгляд: беспокойный или бегающий; 3) наличие или отсутствие слез в ситуации, когда они подразумеваются.

Маркеры реакции кожного покрова: 1) кожа на теле «горит»; 2) покраснение (побледнение) кожных покровов (лица, ушей); 3) появление потливости пальцев, ладоней, подмышек и тела в целом; 4) зуд или сыпь на теле;
5) сморщивание кожи на лбу.

Маркеры пищеварительной системы: обильное выделение слюны и частое ее сглатывание; сухость во рту; боли или колики в области живота; отсутствие аппетита или чрезмерный аппетит.

К дыхательным маркерам относятся: частота дыхания, амплитуда дыхательных волн, соотношение глубины вдоха и выдоха (очень глубокий вдох или выдох).

Мышечные маркеры: повышенное напряжение мышц вдоль спины, поясницы, шеи, плеч или мышечная вялость.

Двигательные маркеры: наличие тремора кистей рук, мышц шеи; подвижная мимика лица; резкие неадекватные движения конечностей; поспешные хаотичные, некоординированные, ошибочные действия и поступки; замедленность или отсутствие необходимых действий; неадекватное поведение; чрезмерная скованность или беспорядочная суетливость; импульсивное или немотивированно-агрессивное поведение; неуверенность походки; вялость; ухудшение координации и точности в движениях.

Физиологические маркеры в нервной системе человека переплетаются с его психическими маркерами.

\section{Психические маркеры.}

Маркеры ощущения и восприятия отражаются в ис-

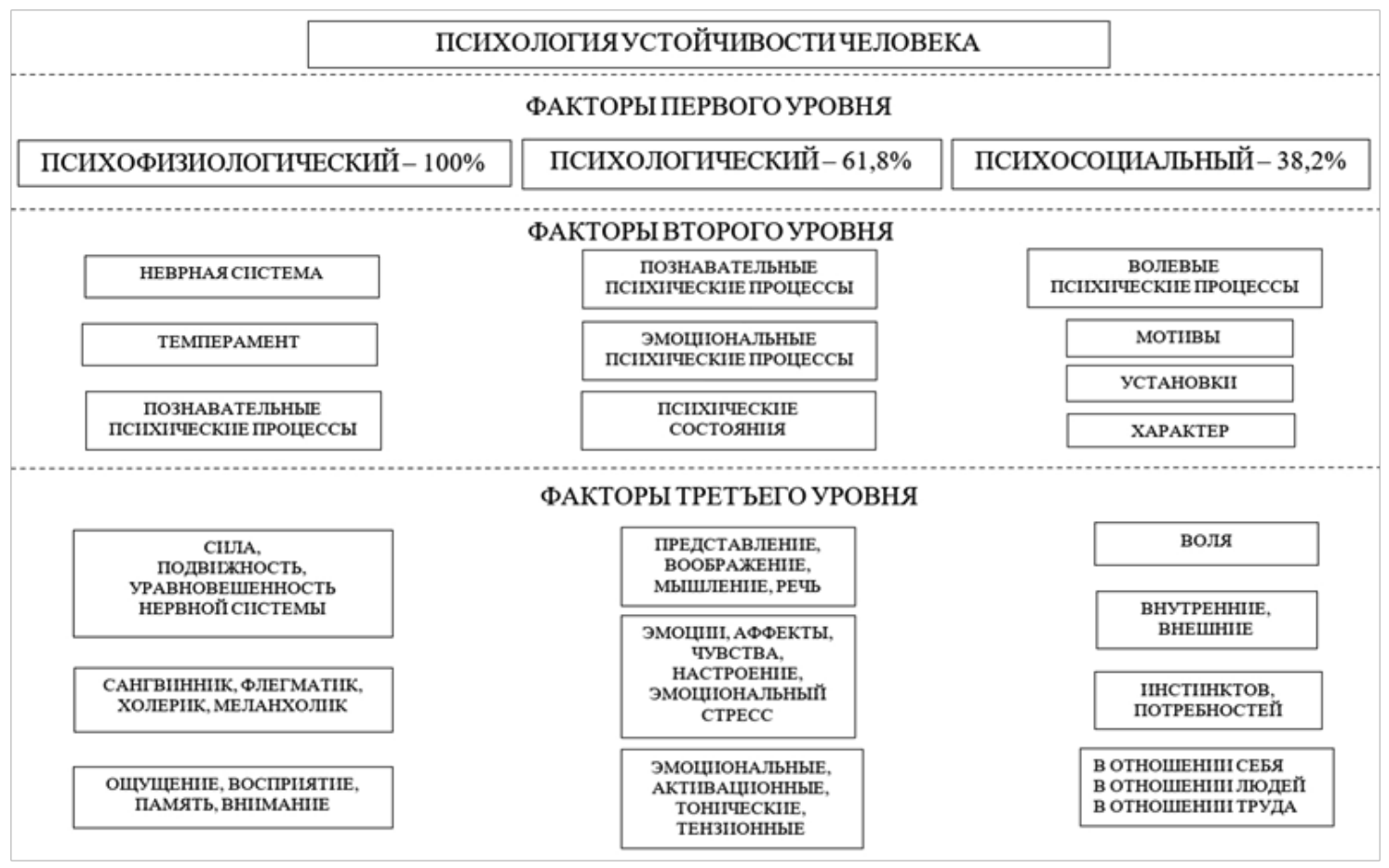

Рис. 3. Развернутая факторная модель устойчивости человека. 
кажении целостного отражения предметов, ситуаций, явлений, возникающих при непосредственном воздействии физических раздражителей на рецепторные поверхности органов чувств через ощущения, что ухудшает обработку информации, полученной от ощущений.

Маркеры отражения дают сбой в подаче информации сознанию из прошлого опыта.

Маркеры внимания выражаются в сбоях восприятия, переработке, накоплении, воспроизведении и передачи информации, что отражается в трудности сосредоточиться, повышенной отвлекаемости, сужения поля внимания.

Маркеры памяти характеризуются ухудшением оперативной памяти, проблемой с принятием, узнаваемостью, воспроизведением следов прошлого опыта, что характеризуется заторможенностью обратной реакции. Память как «сквозной» процесс, перестает обеспечивать преемственность психических процессов, что заключается в сбое воспроизведения нужной информации в сознание, полученной от ощущений, восприятия и представления.

Физиологические и психические маркеры психофизиологического уровня заключаются в восприятии, переработке, воспроизведении и передачи информации на психологический уровень.

Психологический уровень - регистрация эмоций с последующей окраской в психические состояния при мотивационно-побудительных, эмоционально-оценочных и активационно-энергетических реакциях личности, характеризуя ее устойчивость. К маркерам потери устойчивости на психологическом уровне следует отнести эмоции и психические состояния со знаком минус.

Эмоции, как маркер устойчивости, ценны тем, что они интегрированы в человеке, ярко выражены и когда они отрицательные, то по модальности выражены в виде тоски, страха, тревоги, чувстве вины, стыда, гнева, негодования...; по интенсивности и продолжительности проявляются в аффекте, плохом настроении, неадекватных реакциях, драматических чувствах; по напряженности в напряжении.

В зависимости от эмоций формируются соответствующие психические состояния, влияющие на устойчивость человека в пространстве и во времени. Любые существенные для человека изменения биотехносоциума вызывают психологический отклик в виде эмоций и, как следствие, в виде определенного психического состояния.

В соответствии с отрицательной окраской эмоций, выделяются следующие маркеры психических состояний: 1) эмоциональные - меланхолия, тревога, страх, паника...; 2) активационные - отсутствие вдохновения, сосредоточенности, подъема... или перевозбужденность, рассеянность, скука, апатия...; 3) тонические пресыщение, утомление, сонливость...; 4) тензионные напряжение, фрустрация, сенсорный голод, состоянием изоляции, стресс... .

Также следует отметить маркеры познавательного психического процесса. Это маркеры мышления и воображения отражаются в нарушении логики, спутанности мыслей, затрудненности принятия решения, мыслительных сбоях. А также речевые маркеры: необычность в характере речи, ее содержании и стиле высказывания; повышение (занижение) интонации голоса; молчаливость (разговорчивость) несоответствующая обстановке; колебание темпа речи; увеличение незавершенных выражений; возрастание слов «паразитов».

Устойчивость на психологическом уровне для среднестатистического человека является маркером устойчивости на психофизиологическом уровне.

Психосоциальный уровень - регистрация волевого проявления характера субъекта труда в биотехносоциуме при реализации мотивов и установок, выраженных в постановке и достижении цели. Отсутствие волевого проявления направленности характеризует потерю устойчивости человеком как субъектом труда, что регистрируется ниже представленными маркерами.

Маркер 1 - потеря способности сознательным решением из многообразия потребностей выбрать актуальную, сформировать на ее установках нужный мотив, руководствуясь которым, ставится цель. Маркер 1 выражается в неумении преодолеть конфликт потребностей, мотивов и целей, что приводит к страху принять решение, а это, в свою очередь, приводит к бездействию и неопределенности в целом.

Маркер 2 - потеря готовности и способности начать движение к поставленной цели, мобилизуя психофизиологические и психологические возможности, преодолевая внутренние и внешние препятствия. Маркер 2 выражается в неумении преодолеть конфликт выбора поступка и действия, что приводит к отсутствию решительности, смелости, настойчивости, выдержки.

Маркер 3 - потеря способности владеть и управлять собственным поведением. Маркер 3 выражается в деструктивном поведении против себя и общества, что выражается в злоупотребительных вредных привычках, агрессивном поведении против человека или группы людей. 
Маркер 4 - потеря общечеловеческого, группового и личностного мировоззрения и убеждений, объединенных понятиями «жизнь» и «деятельность». Крайним проявлением маркера 4, является суицидальное поведение, терроризм, уничтожение культурных ценностей народов.

В заключении отметим, что в статье представлены два теоретических научных результата. Первый - это определение понятия «устойчивость человека». Отметим, что современная психология не имеет общепризнанного понятийного аппарата по изучению феномена устойчивости применительно к человеку. Сформулированное определение устойчивости человека поможет каждому определиться с объектом и предметом научного иссле- дования по вопросу устойчивости.

Второй научный результат представляет собой факторную модель устойчивости человека. Факторная модель отвечает на ряд важных вопросов: «Что надо исследовать при рассмотрении феномена устойчивости человека?»; «Что надо развивать в человеке для достижения устойчивости как индивида, личности и субъекта труда?»; «В каком направлении следует двигаться при изучении феномена устойчивости человека?».

В качестве примера в статье представлены экспресс методики, которые могут быть ориентиром для исследования феномена устойчивости и её оценки по представленным маркерам.

\section{ЛИТЕРАТУРА}

1. Kamila J. Regin, WiolettaGadecka, Piotr M. Kowalski, Ireneusz M.Kowalski, TadeuszGałkowski. Generational transfer of psychological resilience // Polish Annals of Medicine // Vol.23, Issue 2, June 2016, P.102-107

2. Philip Moons, Koen Luyckx. 25 Psychosocial Issues in Adult Congenital Heart Disease \\ Diagnosis and Management of Adult Congenital Heart Disease \\ 2018, Pages 281-285

3. Sekach M.F., Perelygina E.B., Zotova 0.Y. Intensity of Psychological Health and Personality Psychological Resistance // Procedia - Social and Behavioral Sciences // Vol.86, 10 October 2013, P.88-92

4. Человек в современном мире: кризис и глобализация. Международная междисциплинарная коллективная монография / Сoct., peд. M. Le Chanceaux, И.Э. Соколовская - М.: Энциклопедист-Максимум, $2020-668$ с.

5. Большой психологический словарь / Сост. и общ. ред. Б. Г. Мещерякова, В.П. Зинченко. — СПб: Прайм-ЕВРОЗНАК, 2007. — 672 с.

6. Высшее образование в современном мире: история и перспективы: Международная междисциплинарная коллективная монография. Издание второе, дополненное / Сост., ред. М. ле Шансо, И.Э. Соколовская. - М.: Энциклопедист-Максимум, 2020. - 478 с.

7. Казанков В. Психология устойчивости / Вячеслав Казанков. - [б. м.]: Издательские решения, 2019. - 324 с.

8. L. Campbell-Sills, M.B. Stein. Psychometric analysis and refinement of the connor-davidson resilience scale (CD-RISC): validation of a 10-item measure of resilience J Trauma Stress, 20 (6) (2007), pp. 1019-1028.

9. Ralph L Piedmont. Sixteen Personality Factor Questionnaire In book: Corsini Encyclopedia of Psychology // Chapter • January 2010 with 8,821

10. M.T. Sixbey. Development of the family resilience assessment scale to identify family resilience constructs. University of Florida (2005)

11. Власова 0.А. Антипсихиатрия: становление и развитие. Монография. Москва: Изд-во РГСУ «Союз», 2006 - 221 с. 